\title{
Modified capacity design rule for columns in tall steel MRFs with linear viscous dampers within the framework of Eurocode 8
}

\author{
Konstantinos Kariniotakis ${ }^{1}$ and Theodore L. Karavasilis ${ }^{2, *}$ \\ ${ }^{I}$ School of Engineering, University of Warwick, Coventry CV4 7AL, U.K. \\ ${ }^{2}$ Faculty of Engineering and the Environment, University of Southampton, Southampton SO17 1PJ, U.K.
}

\begin{abstract}
Seismic design codes enforce a set of capacity design rules for steel moment-resisting frames (MRFs) to promote a ductile sway plastic mechanism that involves plastic hinges in beams and column bases. Previous research showed that these capacity design rules may not be effective for tall steel MRFs with viscous dampers under strong earthquakes due to high axial forces in columns. To address this issue, steel MRFs with linear viscous dampers of different stories are designed according to Eurocode 8 along with using a slightly modified conservative capacity design rule. According to this rule, the axial force for the capacity design of a column in the force path of viscous dampers is calculated as the envelope of the axial force from the peak drift state, and, the axial force from the peak velocity state times a scale factor. This envelope axial force value along with the bending moment and shear force from the peak drift state are used to carry out the capacity design of the column by using the formulae of Eurocode 8, i.e. in the same way with a column of a steel MRF without dampers. Incremental dynamic analyses for 44 earthquake ground motions show that the modified conservative capacity design rule results in steel MRFs with viscous dampers that have plastic mechanisms similar to those of steel MRFs without dampers. Moreover, the proposed capacity design rule becomes stricter for buildings with more than 10 stories to address that available analysis methods for structures with dampers underestimate the peak damper forces in the lower stories of yielding tall steel MRFs. More work is needed to extend the findings of this work to the case of steel MRFs with nonlinear viscous dampers.
\end{abstract}

Key-words: Capacity design, Eurocode 8, Plastic mechanism, Steel MRFs, Viscous dampers

*Corresponding author. Theodore L. Karavasilis; E-mail: T.Karavasilis@soton.ac.uk 


\section{Introduction}

Modern technologies for seismic hazard mitigation in building structures, such as passive dampers, have been extensively studied over the past 20 years and are now considered ready for frequent use in seismic-resistant design practice (Christopoulos and Filiatrault 2006). These technologies make it possible to design economically viable buildings that (a) experience significantly less damage than conventional buildings designed according to seismic codes; and (b) return to service within an acceptable short, if not immediate, time after a strong earthquake. The latter is of significant importance as recent strong earthquakes resulted in high losses due to long disruption of the use or occupation of a large number of buildings (New Zealand Treasury Budget Speech 2013).

Fluid viscous dampers are a particular type of passive dampers with well-known advantages including stable seismic energy dissipation capacity and force output that is velocity dependent, and thus, typically out-of-phase with the peak internal forces in the structural members of a building (Symans et al. 2008). As their name implies, fluid viscous dampers consist of a cylinder that encloses fluid and a piston. The dynamic motion of the latter results in force output, $F_{\mathrm{D}}$, given by (Seleemah and Constantinou 1997):

$$
F_{\mathrm{D}}=C \cdot|v|^{a} \cdot \operatorname{sgn}(v)
$$

where $v$ is the velocity across the damper, $a$ is the velocity exponent, $C$ is the damping coefficient, and sgn stands for the signum function. Many research efforts showed that viscous dampers significantly improve the seismic performance of new or existing buildings by reducing story drifts and plastic deformations in main structural members (Symans et al. 2008). Moreover, research efforts evaluated the effectiveness of using viscous dampers to reduce residual displacements as well as damage in velocity-sensitive and accelerationsensitive non-structural components of buildings (Karavasilis and Seo 2011; Pavlou and Constantinou 2006; Wanitkorkul and Filiatrault 2008).

A design procedure for buildings with passive dampers (e.g. yielding, viscous, viscoelastic), which uses a highly damped elastic single-degree-of-freedom system as substitute of the real inelastic multi-degree-of-freedom building, is included in ASCE 7-10 (2010). The total damping of the substitute elastic system is the sum of the inherent, supplemental viscous, and hysteretic (due to yielding) damping. According to ASCE 7-10, the frame of the building that includes the viscous dampers (i.e. the damping system) is designed with the aid of the substitute highly damped system for three different seismic loading situations, i.e. those associated with the peak displacement, acceleration, and 
velocity. The ASCE 7-10 procedure has been validated with numerical simulations of the seismic response of highly damped steel MRFs of up to six stories under the design basis earthquake (DBE) and the maximum considered earthquake (MCE) intensities (Ramirez et al. 2002a; Ramirez et al. 2002b). An alternative design procedure adopts a graphic tool to estimate the peak response of yielding structures with passive dampers with the goal of satisfying multiple target performance objectives (Guo and Christopoulos 2013).

Recent research efforts focused on the collapse assessment of steel MRFs with viscous dampers under earthquake intensities higher than the MCE (Miyamoto et al. 2010). Seo et al. (2014) showed that 4-story steel MRFs with viscous dampers develop plastic mechanisms characterized either by the desired combination of plastic hinges in beams and column bases or by plastic hinges in beams and columns of different stories. Under only few earthquake excitations, plastic mechanisms characterized by the formation of a soft story were also detected. The same work provided evidence that the formation of column plastic hinges in steel MRFs with viscous dampers does not necessarily lead to worst collapse resistance. A recent work extended the study of Seo et al. (2014) to the case of 10-story and 20-story buildings and showed a clear trend of tall steel MRFs with viscous dampers to develop plastic mechanisms that involve column plastic hinges (Karavasilis 2016). The latter work also revealed that column plastic hinges are not particularly detrimental in terms of the collapse resistance and reparability of steel MRFs with viscous dampers. However, the formation of a sway plastic mechanism that involves plastic hinges in beams and column bases is a fundamental requirement of current seismic design codes such as the Eurocode 8 (EC8) (2003). There is therefore an apparent need to explore the possibility of using more conservative capacity design rules for columns in the force path of viscous dampers that will guarantee plastic mechanisms similar to those of steel MRFs without dampers.

In this paper, a slightly modified conservative capacity design rule for the columns of steel MRFs in the force path of viscous dampers is proposed with the goal of achieving the desired global plastic mechanism. The proposed modified capacity design rule becomes stricter for buildings of more than 10 stories to address that current analysis methods for structures with dampers underestimate the peak damper forces in the lower stories of tall steel MRFs. The latter is highlighted by examining the seismic response of prototype buildings of five, 10 and 20 stories using steel MRFs with viscous dampers. Moreover, incremental dynamic analyses (IDA) (Vamvatsikos and Cornell 2002) are conducted to assess the plastic mechanism of the steel MRFs with viscous dampers at different peak story drifts and up to those associated with sidesway collapse. The results of IDA show that the proposed modified capacity design 
rule results in plastic mechanisms similar to those of steel MRFs without dampers. The findings of this work are based on steel MRFs with linear viscous dampers, and thus, further research is needed for the case of steel MRFs with nonlinear viscous dampers.

\section{Proposed capacity design rule for columns in the force path of viscous dampers within the framework of Eurocode 8}

In terms of the capacity design of columns, the beam-column moment ratio method of EC8 is first enforced, i.e.

$$
\sum M_{\mathrm{Rc}} \geq 1.3 \sum M_{\mathrm{Rb}}
$$

where $\Sigma M_{\mathrm{Rc}}$ is the sum of the plastic moments of resistance of the columns and $\Sigma M_{\mathrm{Rb}}$ is the sum of the plastic moments of resistance of the beams; all framing the same joint. It is noted that $M_{\mathrm{Rc}}$ in Equation (2) considers the column axial forces in the columns due to the combination of actions in the seismic design situation.

Apart from the beam-column moment ratio method expressed by Equation (2), the amplified seismic combination method of EC8 is also enforced. In particular, columns are designed against axial forces, bending moments and shear forces (and their combinations) calculated from

$$
\begin{gathered}
N_{\mathrm{Ed}}=N_{\mathrm{Ed}, \mathrm{G}}+1.1 \cdot \gamma_{\mathrm{ov}} \cdot \Omega \cdot N_{\mathrm{Ed}, \mathrm{E}} \\
M_{\mathrm{Ed}}=M_{\mathrm{Ed}, \mathrm{G}}+1.1 \cdot \gamma_{\mathrm{ov}} \cdot \Omega \cdot M_{\mathrm{Ed}, \mathrm{E}} \\
V_{\mathrm{Ed}}=V_{\mathrm{Ed}, \mathrm{G}}+1.1 \cdot \gamma_{\mathrm{ov}} \cdot \Omega \cdot V_{\mathrm{Ed}, \mathrm{E}}
\end{gathered}
$$

where $N_{\mathrm{Ed}, \mathrm{G}}, M_{\mathrm{Ed}, \mathrm{G}}$, and $V_{\mathrm{Ed}, \mathrm{G}}$ are the axial forces, bending moments, and shear forces due to non-seismic actions included in the combination of actions for the seismic design situation; $N_{\mathrm{Ed}, \mathrm{E}}, M_{\mathrm{Ed}, \mathrm{E}}$, and $V_{\mathrm{Ed,E}}$ are the axial forces, bending moments, and shear forces due to the design seismic action; $\gamma_{\mathrm{ov}}$ has a value of 1.25 and accounts for material overstrength; and $\Omega$ is an overstrength factor calculated as the minimum of the ratios of the plastic moment resistance to the internal bending moment in the seismic design situation of all beams.

As pointed by Landolfo (2013), it is unclear why this double capacity design (i.e. use of Equation (2) and Equations (3)-(5)) is necessary, or which method should be given preference in terms of simplicity and efficiency in promoting a global sway plastic mechanism. Since both capacity design rules are enforced, and for consistency, the axial force $N_{\mathrm{Ed}}$ from Equation (3) was used to calculate $\Sigma M_{\mathrm{Rc}}$ in Equation (2) (Bisch et al. 2012).

A slightly modified conservative capacity design rule is proposed for the interior columns in the force path of viscous dampers. In particular, Equation (3) is modified as follows: 


$$
N_{\mathrm{Ed}}=N_{\mathrm{Ed}, \mathrm{G}}+1.1 \cdot \gamma_{\mathrm{ov}} \cdot \Omega \cdot\left(N_{\mathrm{Ed}, \mathrm{E}}, S F \cdot N_{\mathrm{Ed}, \mathrm{E}, \mathrm{V}}\right)
$$

where $N_{\mathrm{Ed,E,V}}$ is the column axial force at the state of the peak velocity under the DBE and SF a scale factor. Equations (2) - (6) are enforced for the capacity design of the columns in the force path of viscous dampers. Moreover, $N_{\mathrm{Ed}}$ from Equation (6) is used to calculate $M_{\mathrm{Rc}}$ in Equation (2). SF is taken equal to 1.0 and its value is re-examined in Section $6 . N_{\mathrm{Ed}, \mathrm{E}, \mathrm{V}}$ can be directly obtained using the multi-modal response spectrum procedure of ASCE 7-10 (2010) for buildings with viscous dampers.

Equation (6) suggests that the column axial force used to perform the capacity design of columns in the force path of viscous dampers is the envelope of the axial force from the peak drift state and the axial force from the peak velocity state times a scale factor. For an elastic or mildly inelastic frame, $N_{\mathrm{Ed}, \mathrm{E}, \mathrm{V}}$ is out-of-phase with $M_{\mathrm{Ed}}$ and $V_{\mathrm{Ed}}$, and therefore, the modified capacity design rule seems rather conservative. It is though noted that for seismic intensities higher than the DBE, peak damper forces increase beyond their design values under the DBE, while inelasticity of the steel MRF may result in unfavourable combinations of axial forces, shear forces, and bending moments in the columns. Therefore, the proposed conservative design rule is justified with respect to the overall goal of promoting a global sway plastic mechanism in tall steel MRFs with viscous dampers.

\section{Seismic design of steel MRFs with and without viscous dampers}

\subsection{Prototype building}

Three prototype steel buildings are designed without and with viscous dampers; the latter with the aid of the proposed capacity design rule discussed in Section 2. The buildings have the same plan view (shown in Fig. 1) and either five, 10 or 20 stories. The buildings are symmetric in both plan and elevation, and therefore, 2D analysis is employed for both design and assessment. To further simplify the study, only one of the two 3-bays (bay width $8 \mathrm{~m}$ ) perimeter MRFs in the longitudinal 5-bays plan direction is considered. The centerline model used for the design assumes rigid full-strength beam-column and column base connections along with a diaphragm constraint for the nodes of each floor to account for the in-plane rigidity of the composite slab. The P- $\Delta$ effects of the gravity loads acting in the tributary area of the perimeter MRF are simulated with the aid of a column with cross-sectional properties (i.e. area, shear area, moment of inertia) equal to the sum of the cross-sectional properties of the gravity columns. 


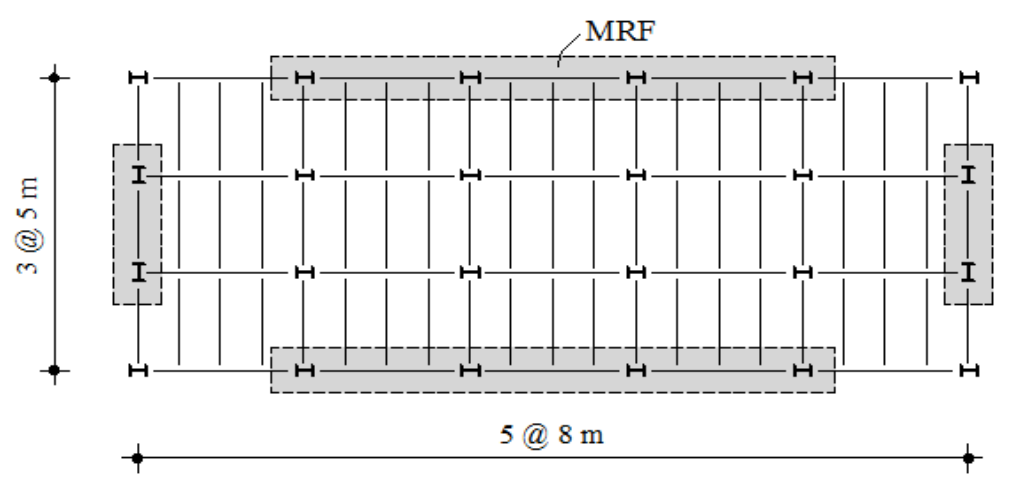

Fig. 1. Prototype building (plan view)

\subsection{Steel MRFs without dampers}

A high-ductility class is adopted in the design of the steel MRFs according to EC8. The elastic design spectrum is defined on the basis of a peak ground acceleration equal to $0.35 \mathrm{~g}$, behavior factor $q$ equal to 6.5, importance factor II and soil type B. S355 and S275 steel grades are assumed for the columns and beams, respectively. The allowable peak story drift, $\theta_{\max }$, is equal to $0.75 \%$ under the frequently occurred earthquake, which has intensity equal to $40 \%$ of the intensity of the DBE. P- $\Delta$ effects are considered through the story drift sensitivity coefficient $\theta$ of EC8. For all designs, the $\theta$ value is less than 0.20 . All the specific rules of EC8 for steel MRFs are enforced, i.e. beams and columns resist design shear forces that are less than $50 \%$ of their plastic shear resistance, while the design axial force in beams is less than $15 \%$ of their plastic axial resistance.

Table 1 lists the steel weight, the fundamental period of vibration $\left(T_{1}\right)$, and the $\theta_{\max }$ under the DBE of the steel MRFs, while Fig. 2 shows their elevation views along with the crosssections of the beams and columns of each story.

\subsection{Steel MRFs with viscous dampers}

Linear fluid viscous dampers (i.e. the velocity exponent $a$ in Equation (1) is equal to 1) are designed for the steel MRFs described in Section 3.2. The dampers are placed in a horizontal configuration and are supported by inverted V steel braces within the interior bay of the steel MRFs as shown in Fig. 2. The braces are designed to be stiff enough to satisfy the condition $\tau / T_{1}<0.02$ (Lin and Chopra 2003), where $\tau$ is the relaxation time defined as the ratio of the damping coefficient to the horizontal stiffness of both braces. Satisfaction of the latter condition practically means that story drift produces damper deformation rather than brace deformation, and therefore, the supplemental damping provided by the dampers can be 
calculated with reasonable accuracy by assuming that braces are axially rigid (Lin and Chopra 2003). Dampers are designed for a supplemental equivalent viscous damping ratio $\xi_{\text {eq }}$ equal to $17 \%$ at the fundamental period of vibration $T_{1}$. In particular, $\xi_{\mathrm{eq}}$ is calculated by using the formulae proposed by Whittaker et al. (2003), i.e.:

$$
\xi_{\text {eq }}=\frac{T_{1}}{4 \pi} \cdot \frac{\sum_{\mathrm{i}} C_{\mathrm{i}} \cdot\left(\varphi_{\mathrm{i}}-\varphi_{\mathrm{i}-1}\right)^{2}}{\sum_{\mathrm{i}} m_{\mathrm{i}} \cdot \varphi_{\mathrm{i}}^{2}}
$$

where $\varphi_{\mathrm{i}}$ and $\varphi_{\mathrm{i}-1}$ are the first modal displacements of floors $i$ and $i-1$, respectively, and $m_{\mathrm{i}}$ is the seismic mass of floor $i$. Equation (7) suggests that different height-wise distributions of $C_{\mathrm{i}}$ can achieve the target $17 \% \xi_{\text {eq }}$ value. However, previous research of the second author and co-workers showed that a distribution of damping coefficients proportional to the horizontal story stiffness of the steel MRF is both effective and practical in comparison with distributions derived from advanced optimization methods (Whittle et al. 2012). Therefore, $C_{\mathrm{i}}$ is calculated as $C_{\mathrm{i}}=\beta K_{\mathrm{i}}$, where $K_{\mathrm{i}}$ is the lateral stiffness of the story $i$ and $\beta$ a factor calculated directly from Equation (7) for $\xi_{\text {eq }}$ equal to $17 \%$. It should be pointed out that the distribution of dampers may be chosen to be uniform in practical applications to avoid the cost of testing different dampers for a single design project. The total viscous damping ratio, $\xi_{\text {tot }}$ at $T_{1}$ for all steel MRFs with viscous dampers is equal to $20 \%$, i.e. equal to $\xi_{\text {eq }}$ plus the inherent damping ratio, which is assumed equal to $3 \%$. The total damping ratio allows the calculation of an appropriate damping reduction factor (Whittaker et al. 2003), which is then used to reduce the ordinates of the design spectrum. The peak drifts and the corresponding forces in the steel MRF with viscous dampers can be then estimated through a standard response spectrum analysis with respect to the highly damped design response spectrum.

Table 1 lists the steel weight, $T$, and $\theta_{\max }$ under the DBE of the steel MRFs with viscous dampers, while Figure 2 shows their elevation views along with the beam/column crosssections and the damping coefficient of the viscous damper of each story. Table 1 shows that the supplemental $17 \%$ equivalent viscous damping ratio results in steel MRFs with significantly higher seismic performance (i.e. much lower $\theta_{\max }$ values) than that of the steel MRFs without dampers. The modified capacity design rule changed the cross-sections of the interior columns of stories 1 to 8 of the 10-story steel MRF and the cross-sections of the interior columns of stories 5 to 18 of the 20-story steel MRF as shown in Figure 2. No changes were needed for the interior columns of the 5-story steel MRF. It is also noted that the application of the modified capacity design rule increased the steel weight of the 10 -story steel MRF by $5 \%$ and the steel weight of the 20 -story steel MRF by $2 \%$. 


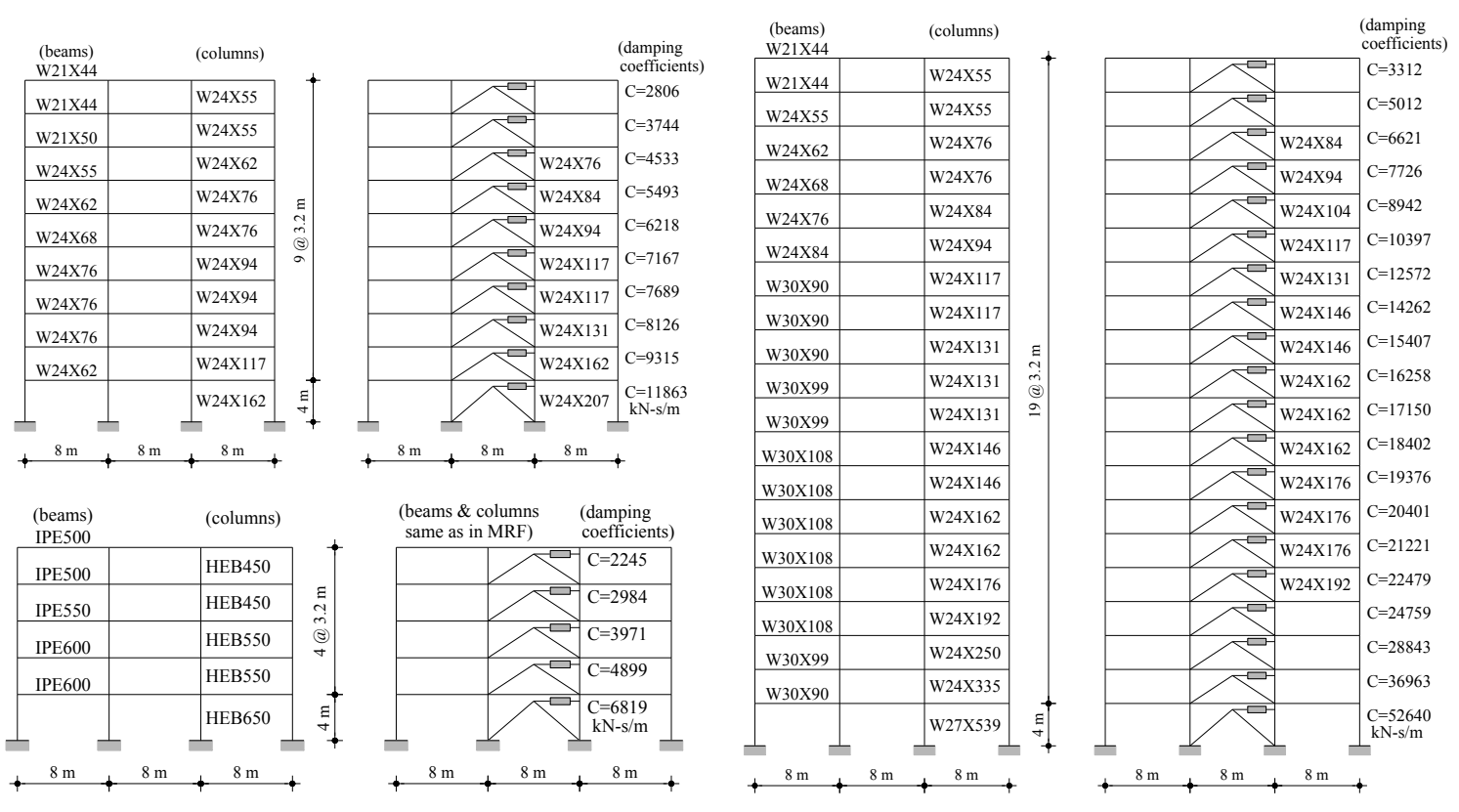

Fig. 2. Elevation view and beam/column cross-sections of the steel MRFs with and without viscous dampers. The damping coefficients of the viscous dampers are also provided. The beam/column cross-sections of the MRFs with viscous dampers are the same with those of the corresponding MRFs without dampers apart from the indicated interior columns

Table 1. Design details of the steel MRFs with and without viscous dampers

\begin{tabular}{lrccc}
\hline \multicolumn{1}{c}{ Frame } & Steel weight $(\mathrm{kN})$ & $T_{1}(\mathrm{sec})$ & $\xi_{\text {tot }}(\%)$ & $\theta_{\text {max,DBE }}(\%)$ \\
\hline MRF & & & & \\
5-story & 254 & 1.28 & & 1.79 \\
10-story & 389 & 2.68 & 3 & 1.52 \\
20-story & 1228 & 3.87 & & 0.89 \\
\hline MRF with dampers & & & & \\
5-story & 254 & 1.28 & & 1.03 \\
10-story & 409 & 2.62 & 20 & 0.89 \\
20-story & 1254 & 3.83 & & 0.52 \\
\hline
\end{tabular}

*Braces are not included in the steel weight of the MRFs with dampers.

\section{Models for nonlinear dynamic analysis and earthquake ground motions}

\subsection{Models}

The OpenSees (2013) software is used to conduct nonlinear dynamic analysis of the steel MRFs with and without dampers. Details of the nonlinear models are shown in Fig. 3. Lumped plasticity beam elements with zero length moment-plastic rotation springs at their ends, which follow the strength and stiffness deterioration rules developed by Lignos and Krawinkler (2011), are used for the steel beams. The Krawinkler model (1978) is used for the 
panel zones. Fiber beam-column elements are used to model the columns to accurately capture moment-axial force interaction effects. Each fiber is assumed to exhibit uniaxial bilinear elasto-plastic stress-strain cyclic behavior. The latter modeling approach results in stable hysteresis without deterioration for the columns; an assumption that is justified for heavy columns of low slenderness (Newell and Uang 2006). Linear viscous dampers are modeled as simple dashpots without considering the limit state of the damper reaching its stroke limit (Miyamoto et al. 2010). It should be noted that strokes of viscous dampers could be extensible up to $\pm 900 \mathrm{~mm}$ upon request (Taylor Devices Inc.), and therefore, the dampers of the steel MRFs examined in this study do not reach their limit states even under very large drifts on the basis of this assumption. The braces supporting the dampers are strong enough to resist the peak damper forces without buckling or yielding, and therefore, they are modeled as elastic truss elements. To account for the presence of the composite slab, an equal horizontal displacement constraint is used for the nodes of each floor. Similarly to the models used for design, a 'lean-on' column is used to account for P- $\Delta$ effects.

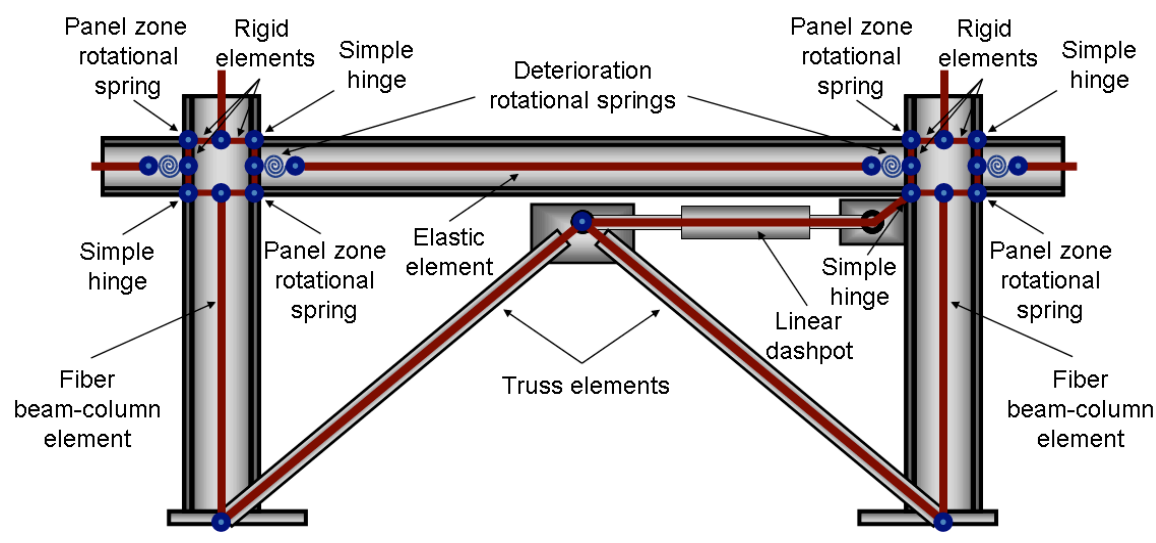

Fig. 3. Details of the model for nonlinear static and dynamic analysis in OpenSees

The integration of the equation of motion of the frames is carried out by using the constant acceleration Newmark method along with the tangent stiffness method for the minimization of the unbalanced forces within each integration time step. Moreover, an automatic technique of decreasing the integration time step was employed to overcome convergence issues. The inherent $3 \%$ damping ratio is represented by a standard Rayleigh damping matrix formulation. A nonlinear force-controlled static analysis under the gravity loads of the seismic design combination serves to provide the initial conditions (i.e. displacements and internal member forces) for the execution of each nonlinear dynamic analysis. 


\subsection{Earthquake ground motions}

Nonlinear dynamic analysis is performed using a set of 22 pairs of far-field ground motions developed by the FEMA P695 project (2009). None of the records shows a distinguishable pulse in its ground velocity time history. All records are recorded on stiff soil or soft rock, while their event magnitudes are within a range of 6.5 to 7.6. The seismic intensity measure used in scaling the ground motions for nonlinear dynamic analysis is the spectral acceleration at the fundamental period of the structure, $S_{\mathrm{a}}\left(T_{1}\right)$, for $5 \%$ damping.

\section{Incremental dynamic analyses and investigation of global plastic mechanisms}

IDA is used to assess and compare the plastic mechanisms of the steel MRFs with and without viscous dampers. For a pair of steel MRF and ground motion, $S_{\mathrm{a}}\left(T_{1}\right)$ is incrementally scaled until global instability occurs, i.e. up to the point that a slight increase of $S_{\mathrm{a}}\left(T_{1}\right)$ results in unbounded increase of the drifts of the steel MRF. The IDA curves for all the steel MRFs and ground motions are shown in Fig. 4. The number of column plastic hinges is used to assess the plastic mechanisms of the frames. It is emphasized that the highly damped steel MRFs have lower peak drifts than those of the MRFs without dampers (e.g. see Table 1 for a comparison among the $\theta_{\max , \mathrm{DBE}}$ of each frame), and therefore, their plastic mechanisms cannot be meaningfully compared at a given $S_{\mathrm{a}}\left(T_{1}\right)$. For that reason, the comparison among the number of column plastic hinges of the frames is carried at the same $\theta_{\max }$ values by performing linear interpolation on the IDA results. Furthermore, to carry out meaningful comparisons among steel MRFs having different stories, the aforementioned median value is normalized with the number of possible column plastic hinge locations (i.e. 152 for the 20story steel MRF, 72 for the 10-story steel MRF, and 32 for the 5-story steel MRF) to yield the median value of the percentage of column plastic hinges.

Fig. 5 shows the median value of the percentage of column plastic hinges against $\theta_{\max }$ for the 5-story, the 10-story and the 20-story steel MRFs with and without dampers. The 5-story MRF with dampers has lower percentage of column plastic hinges compared to the 5-story MRF. Plastic hinges in the 5-story MRF with dampers develop for $\theta_{\max }$ larger than $7 \%$ and their median percentage value is lower than $5 \%$ for $\theta_{\max }$ up to $10 \%$. The 10 -story MRF with dampers has slightly higher percentage of column plastic hinges compared to the 10-story MRF. An appreciable difference between the plastic mechanisms of the two frames is seen for $\theta_{\max }$ larger than $8 \%$. The median value of the percentage of column plastic hinges for the 10 -story steel MRF with dampers is lower than $10 \%$ for $\theta_{\max }$ up to $10 \%$. The aforementioned 
results show that for buildings of up to 10 stories, the proposed simple conservative capacity design rule is very effective and results in steel MRFs with viscous dampers that show plastic mechanisms similar to those of steel MRFs without dampers.
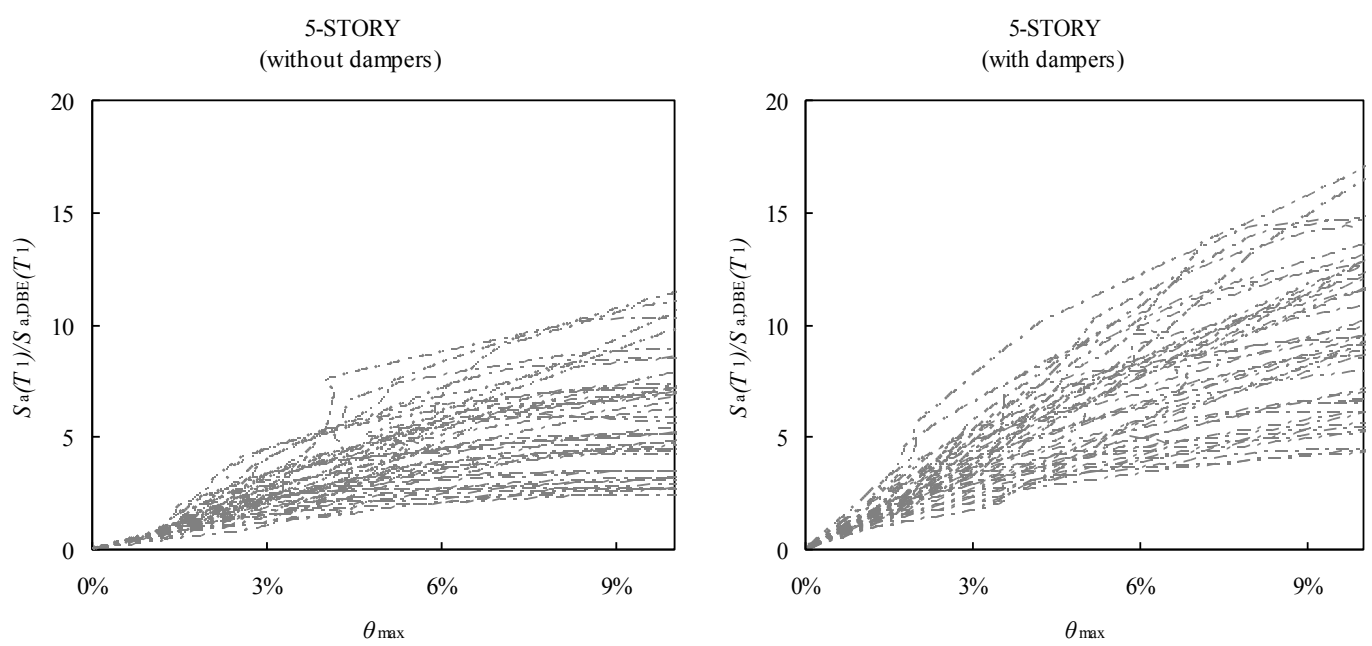

10-STORY

(without dampers)

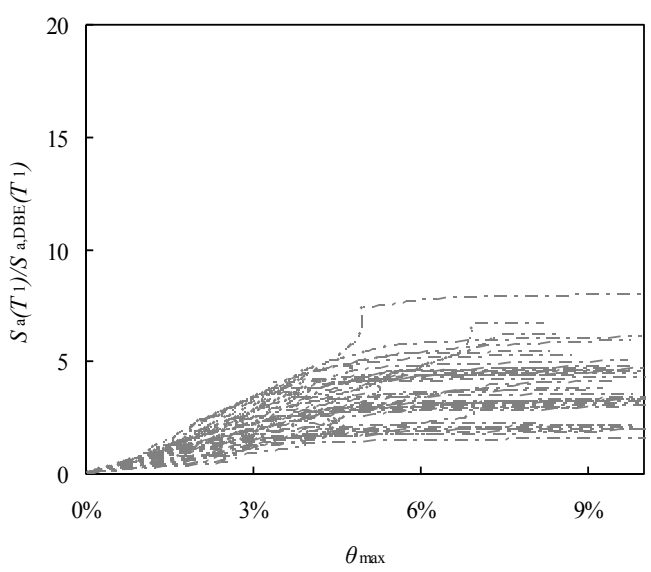

10-STORY

(with dampers)

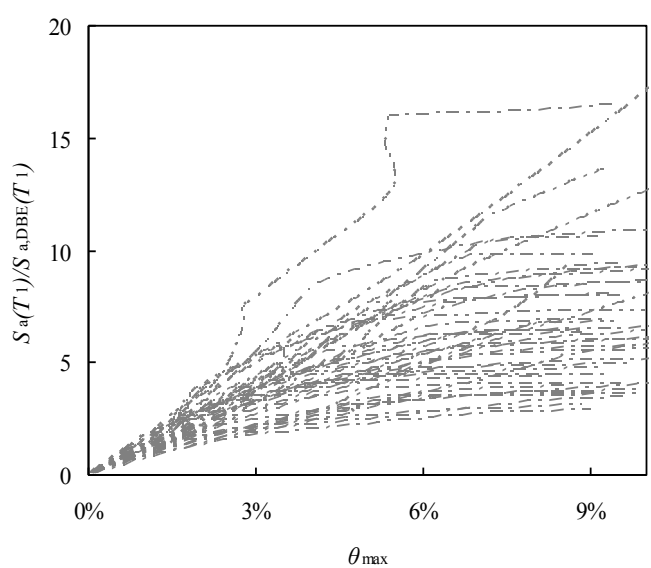

20-STORY

20-STORY

(without dampers)

(with dampers)
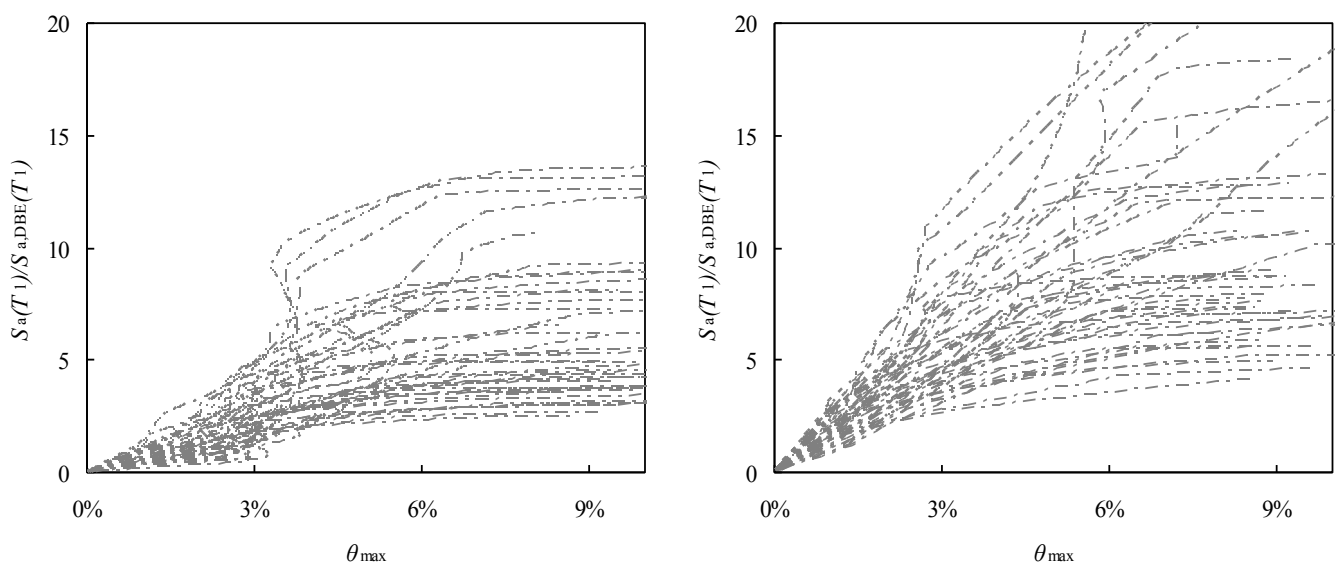

Fig. 4. IDA curves for the steel MRFs with and without viscous dampers 

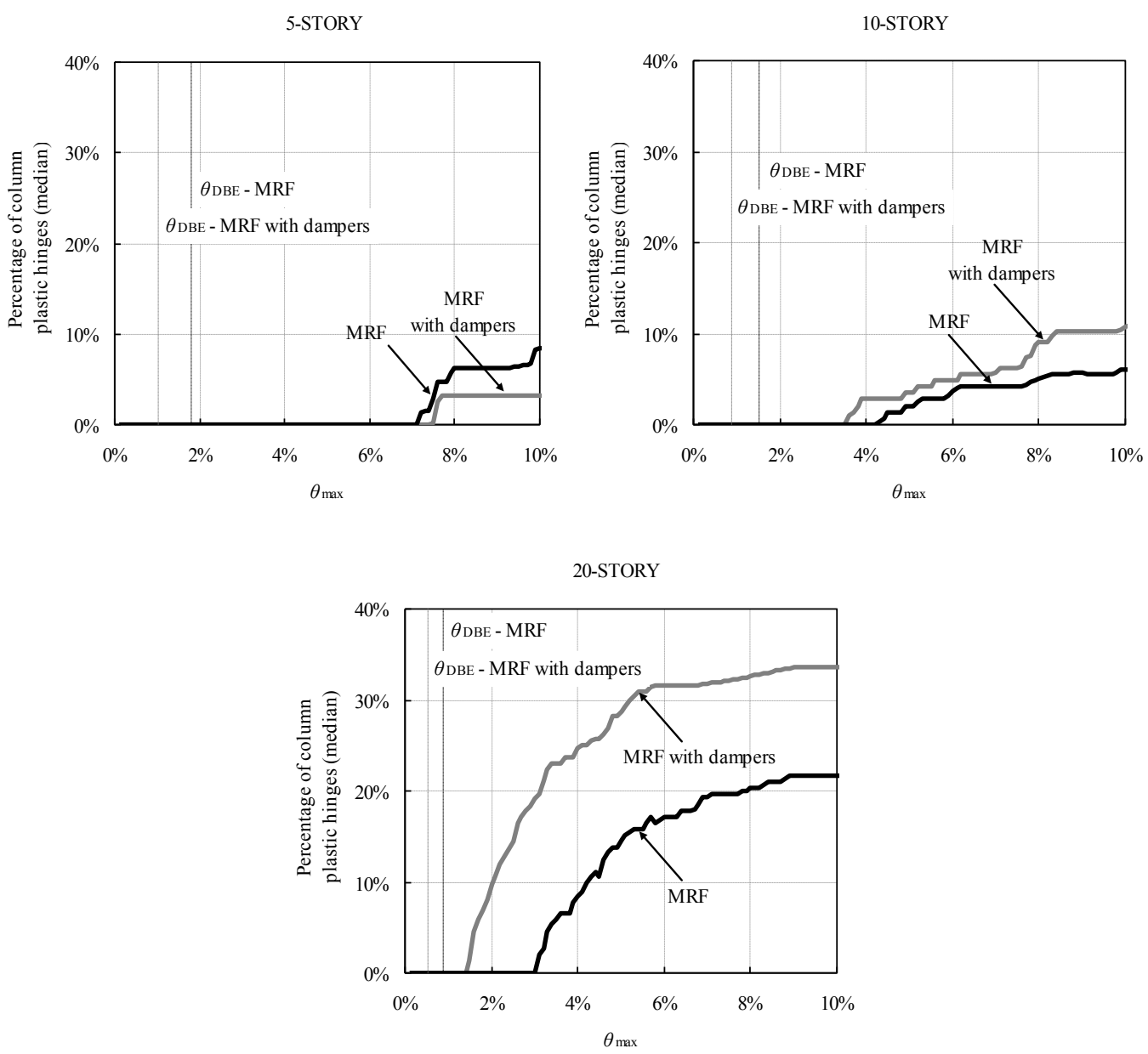

Fig. 5. Percentage of column plastic hinges in the steel MRFs with and without dampers

The 20-story MRF with dampers has a significantly higher percentage of column plastic hinges compared to the 20-story MRF. Column plastic hinges develop at $\theta_{\max }$ equal to $1.5 \%$ and 3\% for the 20-story MRFs with and without dampers, respectively. The percentage of the column plastic hinges at $10 \% \theta_{\max }$ is equal to $35 \%$ and $22 \%$ for the 20 -story MRF with and without dampers, respectively. The aforementioned results show that the proposed capacity design rule needs to become stricter for highly damped steel MRFs of more than 10 stories. Essentially this means that the SF value in Equation (6) needs to become higher than 1.0 to achieve a plastic mechanism similar to that of steel MRFs without dampers. 

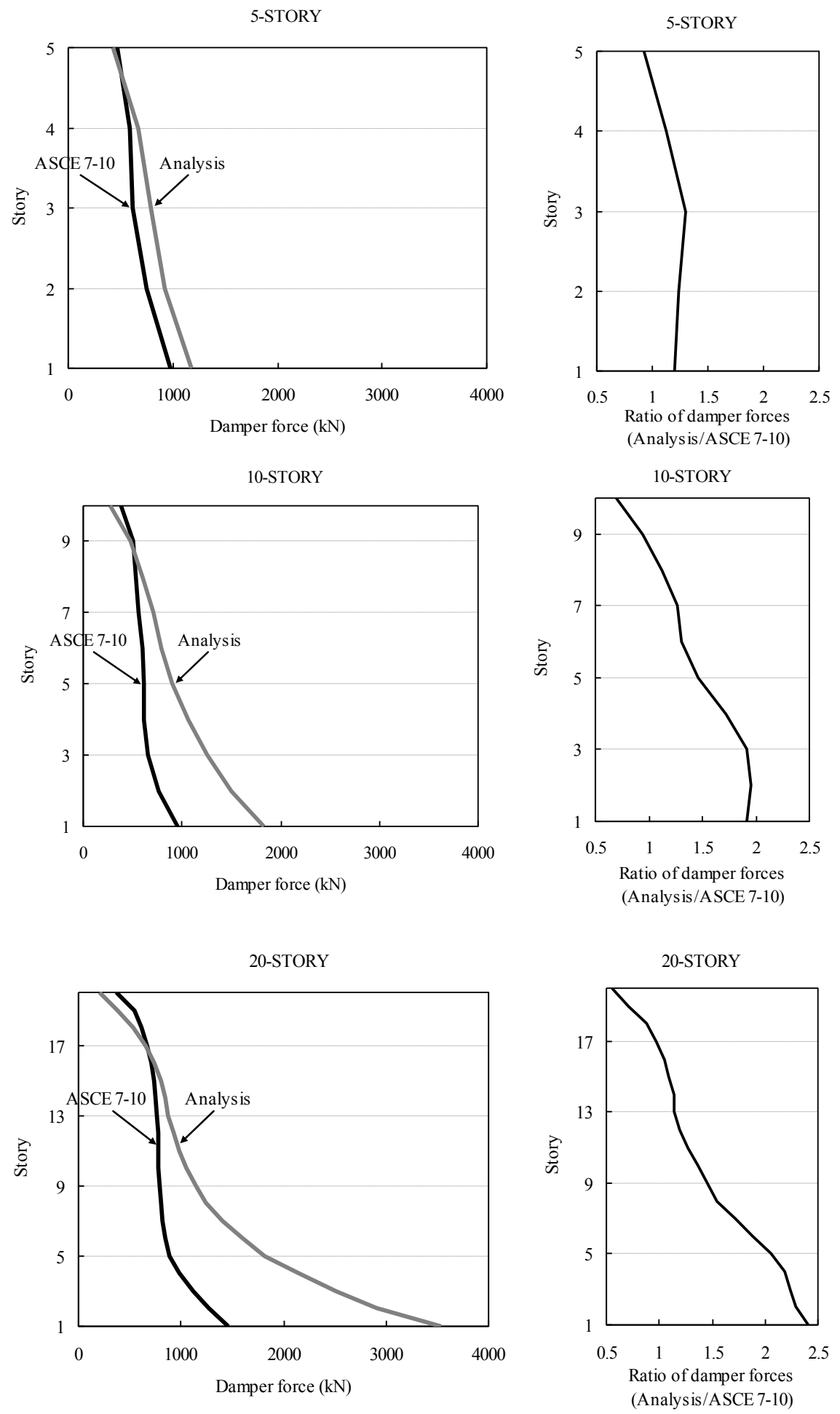

Fig.6. Peak damper forces predicted by ASCE 7-10 and average peak damper forces from nonlinear dynamic analysis for 44 ground motions; both calculated for the DBE seismic intensity

Fig. 6 shows the peak damper forces predicted by the procedure of ASCE 7-10 in comparison with the average values of the peak damper forces from nonlinear dynamic analysis of the three highly damped steel MRFs under the 44 ground motions scaled at the 
DBE. Figure 6 also includes the ratios of the average peak damper forces from analysis over the predicted ones. The values from analysis are higher than the predicted ones and their difference increases for taller steel MRFs. Moreover, their difference increases from the top to the bottom of the building. The maximum ratios are equal to $1.30,1.95$ and 2.41 for the 5story, 10-story and 20-story steel MRFs with dampers, respectively. These results indicate that the ASCE 7-10 procedure underestimates the peak damper forces in the lower stories of tall steel MRFs and further confirm the need for a stricter capacity design rule for columns in buildings of more than 10 stories.

\section{Re-design and assessment of the 20-story steel MRF}

The 20-story steel MRF with viscous dampers is re-designed by using a stricter capacity design rule with the goal of achieving the desired global plastic mechanism. In particular, the design is performed on the basis of a scale factor SF (see Equation (6)) larger than 1.0 and then IDA is carried out to calculate the percentage of column plastic hinges at different $\theta_{\max }$ levels. The latter process is repeated several times until the SF factor that results in a design with plastic mechanism similar to that of the 20-steel MRF without dampers is identified.

Table 2 lists the steel weight, $T$, and $\theta_{\max }$ under the DBE of the final design of the 20-story steel MRF with viscous dampers, while Fig. 7 shows its elevation view with the crosssections of the beams and columns of each story. The associated SF factor has a value equal to 3.5. The stricter capacity design rule results in changes of the interior columns in stories 319 and increases the steel weight by $10 \%$ with respect to the 20 -story steel MRF with viscous dampers designed for SF equal to 1.0 .

Fig. 8 shows the median value of the percentage of the column plastic hinges against $\theta_{\max }$ for the 20-story MRF, the 20-story MRF with dampers designed for SF equal to 1.0, and the 20-story MRF with dampers designed for SF equal to 3.5. The 20-story steel MRF with dampers designed for SF equal to 3.5 has significantly lower percentage of column plastic hinges compared to the steel MRF with dampers designed for SF equal to 1.0, and its behavior approaches that of the steel MRF without dampers. For example, the percentage of the column plastic hinges at $10 \%$ drift is reduced from $34 \%$ for the MRF with dampers designed for SF equal to 1.0 to $25 \%$ for the MRF with dampers designed for SF equal to 3.5 , while the same percentage is equal to $22 \%$ for the steel MRF without dampers. 


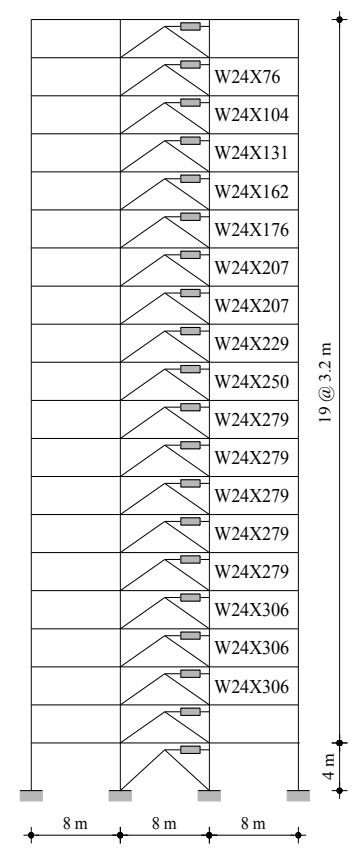

Fig. 7. Elevation view and design details of the 20-story steel MRF with dampers designed for SF equal to 3.5. Beams and columns are the same with those of the MRF with dampers designed for $\mathrm{SF}=1$ apart from the indicated interior columns

Table 2. Design details of the 20-story MRF with dampers designed with SF equal to 3.5

\begin{tabular}{ccccc}
\hline Frame & Steel weight $(\mathrm{kN})$ & $T_{1}(\mathrm{sec})$ & $\xi_{\text {tot }}(\%)$ & $\theta_{\max , \mathrm{DBE}}(\%)$ \\
\hline $\begin{array}{l}\text { MRF with dampers } \\
\text { 20-story }\end{array}$ & 1378 & 3.71 & 20 & 0.52 \\
\hline
\end{tabular}

*Braces are not included in the steel weight.

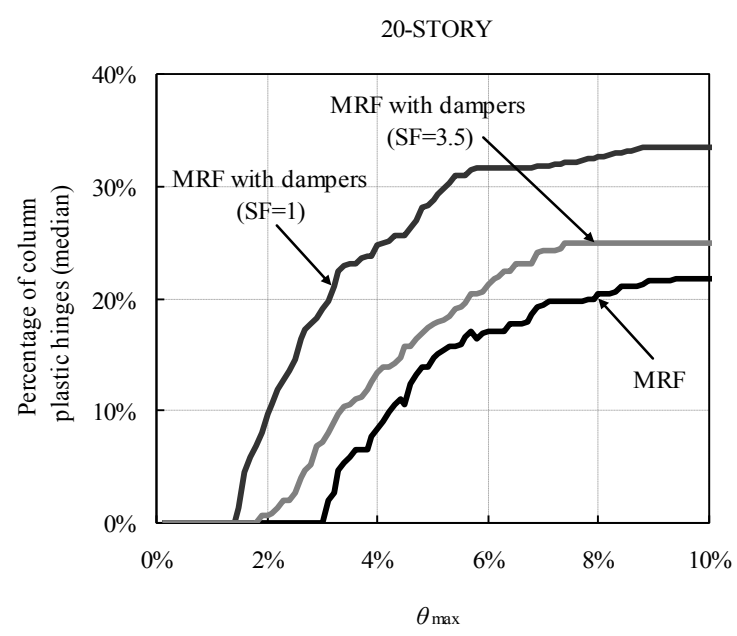

Fig. 8. Percentage of column plastic hinges in steel MRF, MRF with dampers $(S F=1)$ and $\mathrm{MRF}$ with viscous dampers $(\mathrm{SF}=3.5)$. The figure refers to the 20 -story building 
Fig. 9 shows the locations of the column plastic hinges for the 20-story MRF, the 20-story MRF with dampers designed for SF equal to 1.0, and the 20-story MRF with dampers designed for SF equal to 3.5 from nonlinear dynamic analysis under a ground motion scaled to induce to all MRFs a $\theta_{\max }$ equal to $2 \%$. The MRF does not experience column plastic hinges, the MRF with dampers and SF equal to 1.0 has 30 column plastic hinges, and the MRF with dampers and SF equal to 3.5 has 5 column plastic hinges only.

The aforementioned results as well as those in Section 5 show that the proposed modified capacity design rule for columns in the force path of viscous dampers results in highly damped steel MRFs with global plastic mechanisms similar to those of conventional steel MRFs without dampers. The SF factor in the proposed Equation (6) is equal to 1.0 for steel MRFs up to 10 stories and equal to 3.5 for steel MRFs of 20 stories. Linear interpolation can be approximately adopted to calculate the required SF value for steel MRFs with number of stories between 10 and 20 .

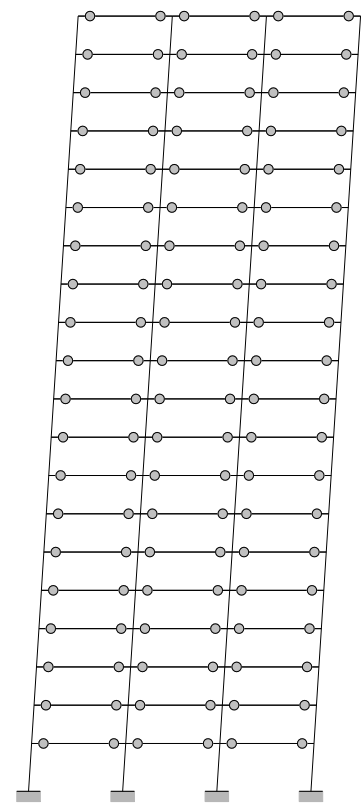

(a)

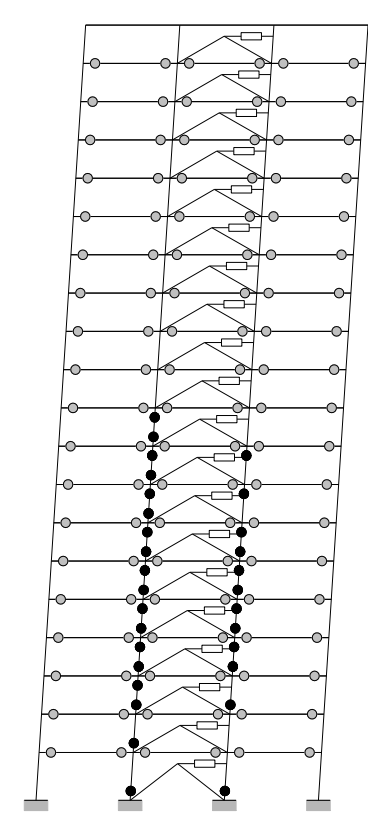

(b)

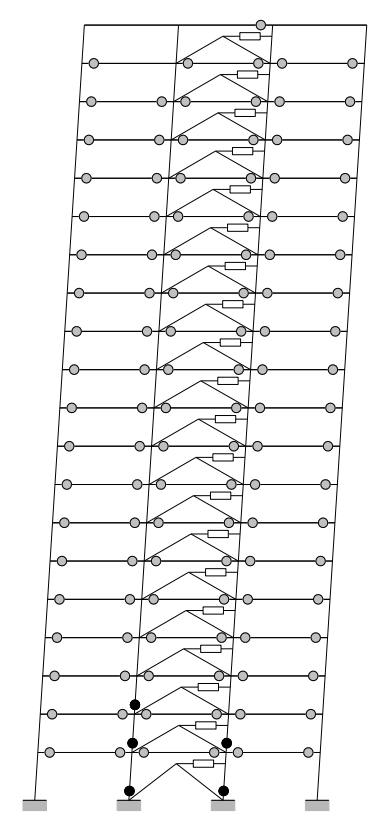

(c)

Fig. 9. Locations of plastic hinges in beams and columns at $\theta_{\max }$ equal to $2 \%$ under a specific ground motion for the 20-story a) MRF; b) MRF with dampers (SF=1); and MRF with dampers $(\mathrm{SF}=3.5)$

The procedure described in Seo et al. (2014) can be used to detect the actual $S_{\mathrm{a}}\left(T_{1}\right)$ value leading to collapse of a steel MRF subjected to a specific ground motion. By employing this procedure, a collapse fragility curve for each of the 20-story steel MRFs is obtained by fitting 
a lognormal distribution to the 44 (i.e. number of ground motions) $S_{\mathrm{a}}\left(T_{1}\right)$ values associated with collapse. Fig. 10 shows the collapse fragility curves of the 20 -story MRF, the 20 -story MRF with dampers and SF equal to 1.0, and the 20-story MRF with dampers and SF equal to 3.5. The $S_{\mathrm{a}}\left(T_{1}\right)$ at $50 \%$ probability of collapse is $6.4 \cdot S_{\mathrm{a}, \mathrm{MCE}}\left(T_{1}\right)$ for the 20 -story steel MRF with dampers and SF equal to 1.0 , while the same quantity is equal to $7.3 \cdot S_{\mathrm{a}, \mathrm{MCE}}\left(T_{1}\right)$ for the 20 -story MRF with dampers and SF equal to 3.5. These values show that the application of the stricter capacity design rule for the columns of the 20-story steel MRF with viscous dampers does not result in significant benefit in terms of the collapse resistance. However, the aforementioned $14 \%$ increase in collapse resistance could be significant in the case of lightweight steel MRFs with viscous dampers designed to have similar drift performance with that of MRFs without dampers. For such frames, achieving a global sway plastic mechanism is a fundamental requirement of seismic codes that should be satisfied before establishing other minimum requirements (e.g. allowable value of the story drift sensitivity coefficient $\theta$ ) that will allow using viscous damper to reduce steel weight without compromising the seismic performance. The authors will present the results of research that establishes such requirements in a near future publication.

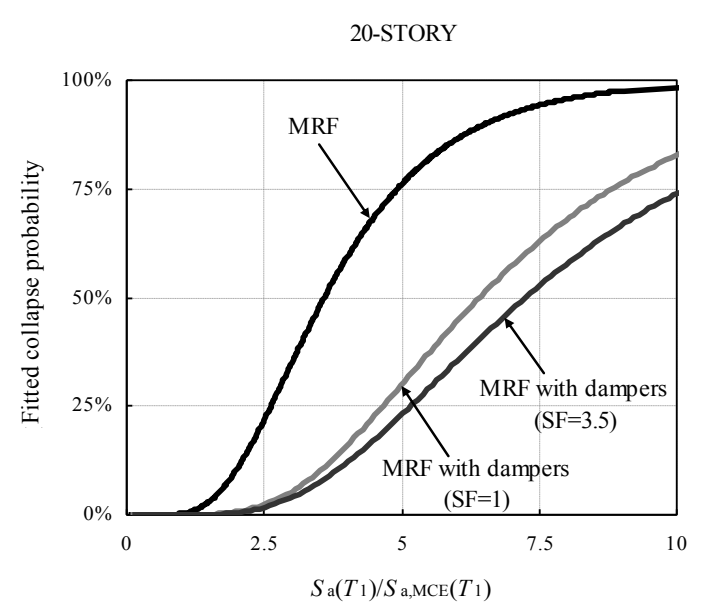

Fig. 10. Collapse fragility curves of the 20-story MRF, 20-story MRF with dampers and SF equal to 1.0 , and 20-story MRF with dampers and SF equal to 3.5

\section{Summary and conclusions}

Previous research showed that the capacity design rules of current seismic codes may not be effective for tall steel MRFs with viscous dampers under strong earthquakes due to high axial force demands in columns. To address this issue, steel MRFs with viscous dampers of different stories were designed according to Eurocode 8 along with using a slightly modified conservative capacity design rule. According to this rule, the axial force for the capacity 
design of a column in the force path of viscous dampers is calculated as the envelope of the axial force from the peak drift state, and, the axial force from the peak velocity state times a scale factor. This envelope axial force value along with the bending moment and shear force from the peak drift state are used to carry out the capacity design of the column by using the formulae of Eurocode 8, i.e. in the same way with a conventional steel MRF without dampers. Incremental dynamic analyses for 44 earthquake ground motions were carried out for all steel MRFs with and without viscous dampers. The results of analyses show that the modified conservative capacity design rule results in highly damped steel MRFs with plastic mechanisms similar to those of steel MRFs without dampers. Moreover, the proposed capacity design rule becomes stricter for buildings with more than 10 stories to address that available analysis methods for structures with dampers underestimate the peak damper forces in the lower stories of yielding tall steel MRFs. The aforementioned scale factor is equal to 1.0 for buildings with less than 10 stories and equal to 3.5 for buildings of 20 stories. Linear interpolation is suggested to approximately calculate the appropriate scale factor value for buildings with number of stories between 10 and 20; though more research is needed to establish its value with more accuracy. In particular, buildings with different geometries, supplemental damping ratios and/or nonlinear viscous dampers should be examined.

\section{References}

ASCE 7-10 (2010) Minimum Design Loads for Buildings and Other Structures. American Society of Civil Engineers, Reston, Virginia

Bisch P, Carvalho E, Degee H, Fajfar P, Fardis M, Franchin P, Kreslin M, Pecker A, Pinto P, Plumier A, Somja H, Tsionis G (2012) Eurocode 8: Seismic design of buildings worked examples. JRC, European Commission

Christopoulos C, Filiatrault A (2006) Principles of passive supplemental damping and isolation. IUSS press

Eurocode 8 (2013) Design of Structures for Earthquake Resistance.

FEMA (2009) Quantification of building seismic performance factors. FEMA P695 Report. Federal Emergency Management Agency, Washington D.C.

Guo JWW, Christopoulos C (2013) Performance spectra-based design method for the seismic design of structures equipped with passive supplemental damping systems. Earthq Eng Struct Dynam 42(6):935-952 
Karavasilis TL, Seo C-Y (2011) Seismic structural and non-structural performance evaluation of highly damped self-centering and conventional systems. Eng Struct 33:22482258

Karavasilis TL (2016) Assessment of capacity design of columns in steel moment resisting frames with viscous dampers. Soil Dynam Earthq Eng 88:215-222

Krawinkler H (1978) Shear design of steel frame joints. Eng J AISC 15(2):82-91

Newell J, Uang CM (2006) Cyclic behaviour of steel columns with combined high axial load and drift demand. Report No. SSRP-06/22. Department of Structural Engineering, University of California, San Diego, La Jolla

Landolfo R (2013) Assessment of EC8 provisions for seismic design of steel structures. ECCS TC13, Seismic Design

Lignos DG, Krawinkler H (2011) Deterioration modeling of steel components in support of collapse prediction of steel moment frames under earthquake loading. J Struct Eng 137(11):1291-1302

Lin W, Chopra A (2003) Earthquake response of elastic single-degree-of-freedom systems with nonlinear viscoelastic dampers. J Eng Mech 129(6):597-606

Miyamoto HK, Gilani AS, Wada A, Ariyaratana C (2010) Limit states and failure mechanisms of viscous dampers and the implications for large earthquakes. Earthq Eng Struct Dynam 39(11):1279-1297

New Zealand (2013) Treasury Budget Speech. Available online: http://www.treasury.govt.nz/ budget/2013/speech/06.htm (accessed on 14 May 2014)

OpenSees (2013) Open system for earthquake engineering simulation. Pacific Earthquake Engineering Research Center, University of California at Berkeley, Berkeley, CA

Pavlou E, Constantinou MC (2006) Response of nonstructural components in structures with damping systems. J Struct Eng 132(7):1108-1117

Ramirez OM, Constantinou MC, Gomez JD, Whittaker AS, Chrysostomou CZ (2002a) Evaluation of simplified methods of analysis of yielding structures with damping systems. Earthq Spectra 18(3):501-530

Ramirez OM, Constantinou MC, Whittaker AS, Kircher CA, Chrysostomou CZ (2002b) Elastic and inelastic seismic response of buildings with damping systems. Earthq Spectra 18(3):531-547

Seleemah A, Constantinou MC (1997) Investigation of seismic response of buildings with linear and nonlinear fluid viscous dampers. NCEER 97-0004. National Center for Earthquake Engineering Research, Technical report, Buffalo 
Seo C-Y, Karavasilis TL, Ricles JM, Sause R (2014) Seismic performance and probabilistic collapse resistance of steel moment resisting frames with fluid viscous dampers. Earthq Eng Struct Dynam 43(14):2135-2154

Symans M, Charney F, Whittaker A, Constantinou M, Kircher C, Johnson M, McNamara R (2008) Energy dissipation systems for seismic applications: current practice and recent developments. J Struct Eng 134(1):3-21

Taylor Devices Inc. Accessible to http://www.taylordevices.com.

Vamvatsikos D, Cornell CA (2002) Incremental dynamic analysis. Earthq Eng Struct Dynam 31(3):491-514

Wanitkorkul A, Filiatrault A (2008) Influence of passive supplemental damping systems on structural and nonstructural seismic fragilities of a steel building. Eng Struct 30(3):675-682

Whittaker A, Constantinou M, Ramirez O, Johnson M, Chrysostomou C (2003) Equivalent lateral force and modal analysis procedures of the 2000 NEHRP provisions for buildings with damping systems. Earthq Spectra 19(4):959-980

Whittle J, Williams MS, Karavasilis TL, Blakeborough A (2012) A comparison of viscous damper placement methods for improving seismic building design. J Earthq Eng 16:540-560 